\title{
Óbitos de cães e gatos durante procedimentos de banho e tosa: uma realidade pouco conhecida no Brasil
}

Anna Carolina Barbosa Esteves Maria ${ }^{1}$ Adriana de Siqueira ${ }^{1}$
Fernanda Aucielo Salvagni’

Paulo César Maiorka’

\section{Death of dogs and cats during grooming procedures: a little known reality in Brazil}

\section{Resumo}

Com o crescimento do mercado pet e suas inovações, proprietários de cães e gatos encontram cada vez mais alternativas para a saúde e bem-estar de seus animais. Os estabelecimentos de priet́rios não vem ganhando espaço, uma vez que muitos proJa higiene do seus animas. Porm, o que multos propretrios até mesmo médicos vetentas desconhecm, e que cates e

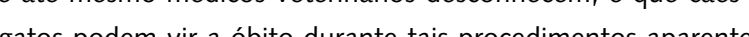
gatos podem vir a ob vio dunante tals procedmentos aparentemente inofensivos, principalmente devido ao estresse. A morte decorrente de estresse pode ocorrer tanto em animais debilitados quanto saudávis, independente da raça, idade ou sexo. Em un mbiente de banho e tosa, a presença de agentes estressores nevitável, mas algun mas regras devern ser seguidas a fim de minimizar o estresse nestes animais. Este trabalho tem como objetivo fornecer informaçōes acerca da causa de morte nessas circunstâncias e suas implicações legais.

\section{$\rho$}

\section{Summary}

With the growth of the pet market and its innovations, owners of dogs and cats have increasingly alternatives for the health and welfare of their animals. Establishments of bathing and grooming are becoming more popular, as many owners do not have the time and abilty to provide the adequate hysiene of their pets. However many pet owness and eve veteriarans ae unatse that dogs and cats can die during bathing or sooning due to stress. Death relted to stess may happen to sick or heathy

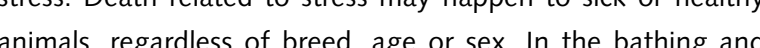
grooming ancess of breed, age or sex. In the bathing and but som envinment, the presence of stressors is inevitable, anim fals. This paper aims to provide information about the cause of death of these animals and the legal implications involved.
Medicina vetetináaria legal. Pet shop. Estresse. Keywords Forensic veterinary medicine. Crooming. Stress
Pulmonary hemorrhage. Trauma. Cruelty.

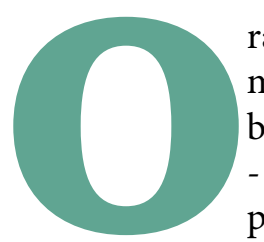

mo pet no Brasil vem crescendo consideravelnos ńltimos anos movimentando mais de 15 bilhões de reais em 2013, segundo a Abinpet (2014) Associação Brasileira da Indústria de Produtos para Animais de Estimação, ficando atrás apenas dos Estados Unidos com o maior faturamento mundial do ramo.

O número de estabelecimentos conhecidos popularmente como "pet shops" - que além de comercializarem alimentos, medicamentos e acessórios também contam com servicos de banho e tosa - vem aumentando número chega a mis de 4.000 estacles.

Quan os serviços de banho etosa se destacam, sendo o segundo maior faturamento desse mercado no Brasil, tendo a venda de alimentos em primeiro lugar. A procura por estes serviços vem apresentando um rápido crescimento, com aumento de $26 \%$ no ano de 2013 , uma vez que muitos proprietários não dispõem de tempo e habilidade para a realização da higiene adequada de seus animais (ABINPET, 2014).

Um ambiente de banho e tosa pode parecer um local inofensivo, mas até mesmo um animal saudável pode vir a óbito durante tais procedimentos em decorrência de traumas físicos (Figura 1) e, principalmente, de estresse (MARIA; REGO; MAIORKA, 2013).

Animais que apresentam ansiedade, agressividade e pânico du-

Ante o banho ou tosa, em decorrência de estresse, podem vir a óbito cor colapso respir vón (O) respiratório ainda não está claro (MARIA, 2010). 


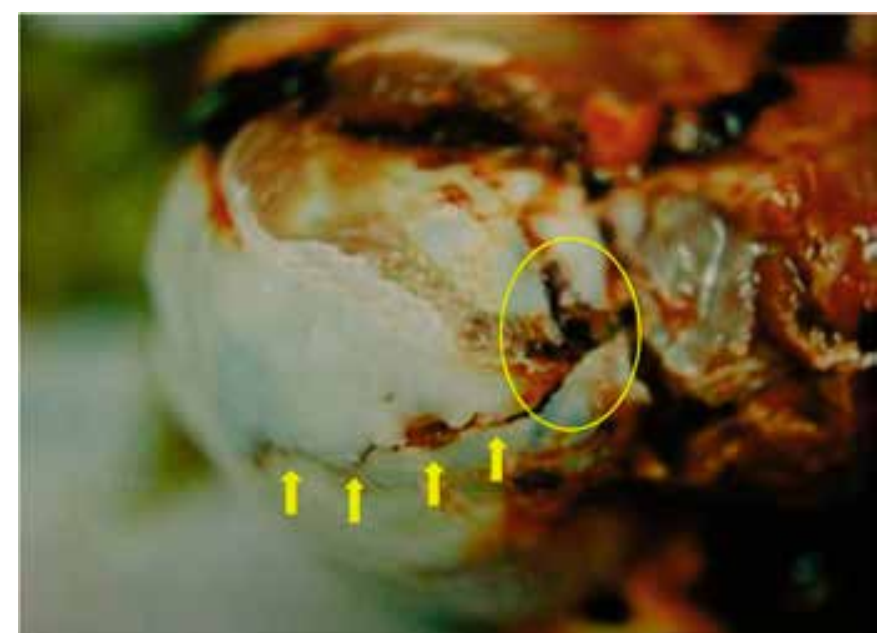

Figura 1 - Regiäa cefalica, căo: fratura de ossos occupt
sionadas durante procedimentos de banho e tosa

$\mathrm{O}$ estresse começou a ser estudado mais detalhadamente em 1936 por Hans Selye, um médico endocrinologista da Universidade de Montreal - Canadá, até os dias de hoje, ainda é tema de muitos estudos, sendo alguns até controversos. Segundo ele, "estresse é o estado manifestado por uma síndrome específica que consiste manifestado por uma sindrome especifica que consiste um sistema biológico", portanto, qualquer estímulo que um sistema biológico", portanto, qualquer estimulo que
desafie a homeostase de um indivíduo é um estressor; as mudanças ocorridas na função biológica para manter a homeostase são a resposta do animal ao estresse (SELYE 1936; SELYE, 1956; MOBERG, 2001).

Os agentes estressores podem ser agrupados baseados em sua duração, intensidade e características (Quadro 1) (PACAK; MCCARTY, 2007).

\begin{tabular}{|l|l|l|}
\hline DURAÇÃO & INTENSIDADE & \multicolumn{1}{c|}{ CARACTERISTIICAS } \\
\hline Agudo & Baixa & $\begin{array}{l}\text { - Físicos: frio, calor, radiação, } \\
\text { barulho, vibração, entre outros; } \\
\text { - Químicos: drogas } \\
\text { medicamentosas, substâncias } \\
\text { tóxicas, insulina, entre outros; } \\
\text { - Psicológico: ansiedade, medo, } \\
\text { frustração, entre outros; } \\
\text { - Social: dominância entre animais, } \\
\text { introdução de novos indivíduos no } \\
\text { habitat, transferência de habitat, } \\
\text { entre outros. }\end{array}$ \\
\hline
\end{tabular}

Quadro 1 - Classificacăo dos agentes estressores
Fonte: Adaptado de Pacake Mccarty (2007).

Em um ambiente de banho e tosa, são observados diversos agentes estressores, principalmente físicos, psicológicos e sociais. A partir do momento que o animal é retirado de seu habitat e introduzido em um novo ambiente, já há motivo suficiente para causar um quadro de estresse, mesmo que seja mínimo e possivelmente imperceptível. Até mesmo um animal, frequentador assíduo de uma pet shop, onde seja manipulado sempre pelo bo dempre perce grande rotividale de pessos e de anis proporiogrande rotatividade de pessoas e de animais, proporcionando novos estímulos visuais, auditivos e olfativos, que diferem do que o animal está habituado, podendo iniciar, portanto, um quadro de estresse (MARIA, 2010).

Tanto cães como gatos podem se estressar em tais procedimentos, independente da raça, sexo e idade, ma algumas raças e idades exigem um pouco mais de atenção por parte dos médicos veterinários, tosadores e banhistas (MARIA, 2010)

Cães de pequeno porte, principalmente poodle, lhasa-apso, yorkshire, shih-tzu e maltês (Gráfico 1), além de erem os cães que mais frequentam o banho e tosa Maria (2010), são os animis com maior probabilida de óbito por estresse, pois ap mesen probabe

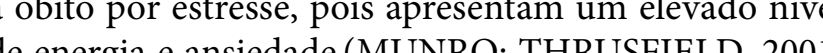
ARHANT et al., 2010).

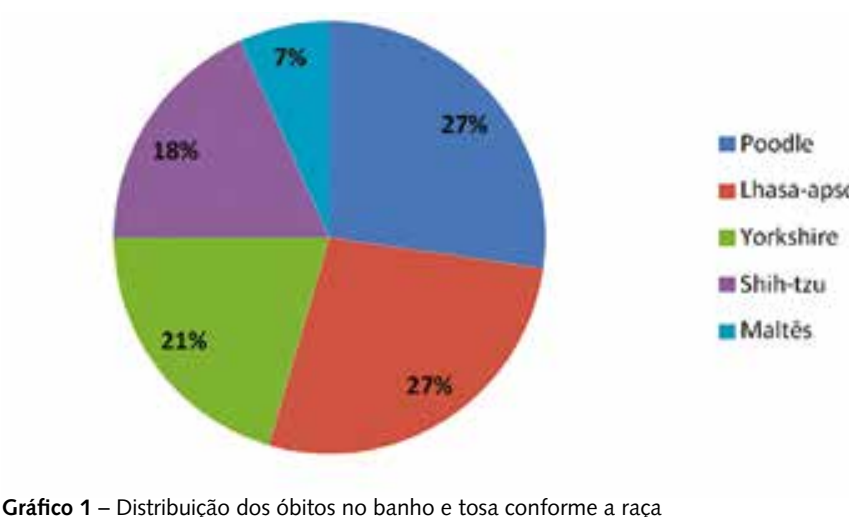
Gráicco 1 - Distribuiçăa dos óbitos no banho e tosa conforme a raça Fonte: Adaptado de Maria (2010.

Os gatos, independente da raça, são extremamente suscetíveis às alterações ambientais, as quais podem levar a alteraçóes comportamentais e ao surgimento de sinais clínicos de sutis a graves. O simples ato de levá-los ao médico veterinário ou à pet shop pode causar inúmeras alterações nos parâmetros fisiológicos, que devem ser cuidadosamente observadas e avaliadas, tais como convulsões, despigmentação cutânea repentina, medo, excitabilidade, depressão, anorexia, aversão a certos loexcitabilidade, depressão, anorexia, aversão a certos loch, vomito, diarreia e agressividade (BEAVER, 2005). inglês e francês, pequinês, boxer e pug, além de gatos da raça persa, himalaio, dentre outros, também apresentam grande probabilidade de vir a óbito por estresse durante o banho e tosa (MARIA, 2010). Tais raças apresentam anormalidades anatômicas congênitas das vias aéreas superiores e quando os animais são submetidos a esforços físicos excessivos ou a temperaturas ambientais muito

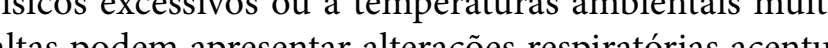
síndrome do braquicefálico (FINGLAND, 2008).

sindrome do braquicefálico (FINGLAND, 2008).
A idade dos animais também pode interferir na forma

A idade dos animais também pode interferir na forma
que o organismo irá adotar para reconhecer e enfrentar o que o organismo irá adotar para reconhecer e enfrentar o
estresse. Animais jovens com menos de um ano de idade estresse. Animais jovens com menos de um ano de idade também apresentam maior probabilidade de vir a óbito pois são extremamente agitados, o que dificulta o seu manejo por parte do tosador ou do banhista (MUNRO THRUSFIELD, 2001).

Apesar dos animais idosos não serem uma parcela significativa entre os óbitos por estresse, eles também necessitam de atenção especial, pois a probabilidade de apresentarem alguma doença preexistente é alta, como nos casos de cardiomiopatias, endocrinopatias e neoplasias (FIGHERA et al., 2008). Em uma situação de estresse, um animal que se encontre nestas condições pode vir a óbito facilmente, pois o seu organismo não dispõe de mecanismos suficientes para reverter determinada situação a tempo (PACAK; MCCARTY, 2007). Gatos idosos, em especial, apresentam uma maior susceptibilidade ao estresse, devido à maior dificuldade de adaptação a novas situações (BEAVER, 2005).

Para diminuir a incidência de óbitos por estresse durante o banho e tosa, funcionários e principalmente médicos veterinários precisam estar atentos a algun sinais de estresse nos animais relacionados no quadro baixo (Qundro 2). No entanto alguns anima não apresentar qualquer sinal. (MARIA, 2010).

\begin{tabular}{|l|l|}
\hline \multicolumn{1}{|c|}{ PARÂMETROS FISIOLÓGICOS } & \multicolumn{1}{|c|}{ COMPORTAMENTO } \\
\hline Aumento da frequência cardiaca & Agressividade \\
Aumento da frequência respiratótria & Agitação \\
Mucosas cianóticas & Medo \\
Perda momentânea da consciência & Cauda abaiixada/entre as pernas \\
\hline \multicolumn{2}{|l|}{} \\
\hline
\end{tabular}

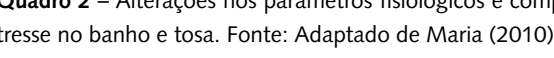

A maioria dos animais estressados vem a óbito em decorrência de hemorragia e edema pulmonares (Figura 2,3 e 4). Portanto ao primeiro sinal de alteração nos parâmetros fisiológicos do animal, o procedimento de panho ou tosa deve ser interrompido e o médico vo terinário deve ser acionado imediatamente, uma vez que em grande parte dos casos o obito ocorre em poucos minutos após o início dos sinais (MARIA, 2010).

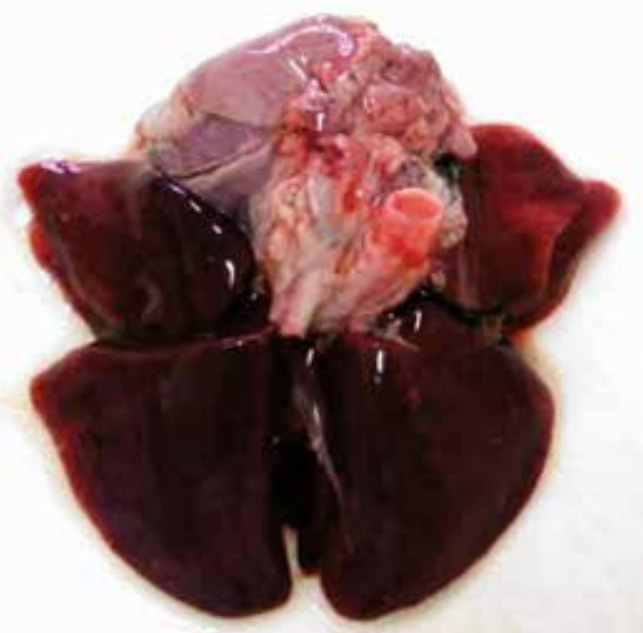

figura 2 - Pulmão, cẫo: órgãa apresentando coloraçăo vermelho escuro distrtibuida difiusamente por todo parénquima, sugerindo quadro de hemorragia severa. Quadro observado

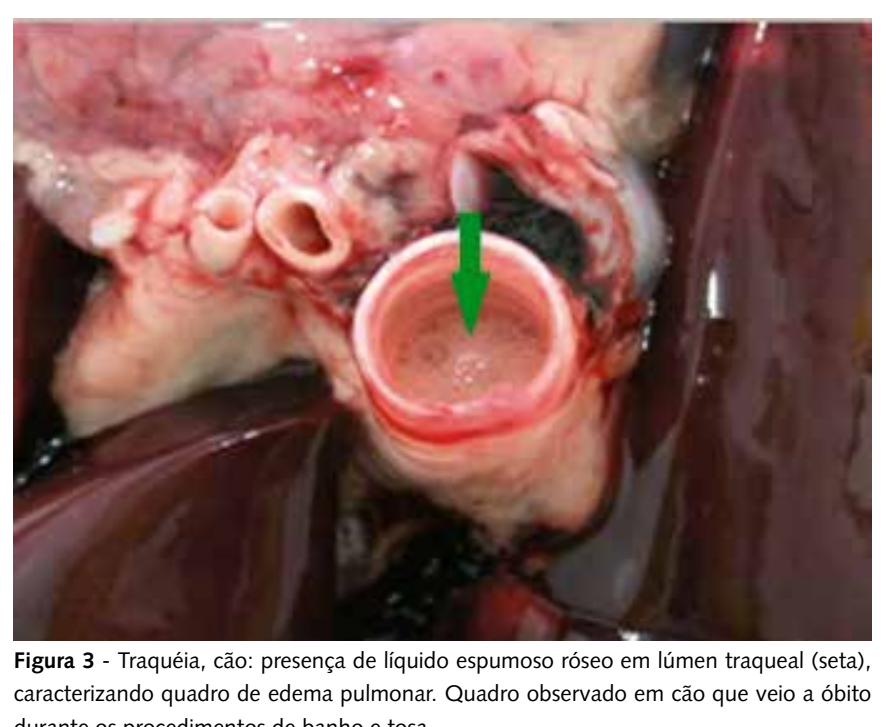
durante os procedimentos de bama pulmonar

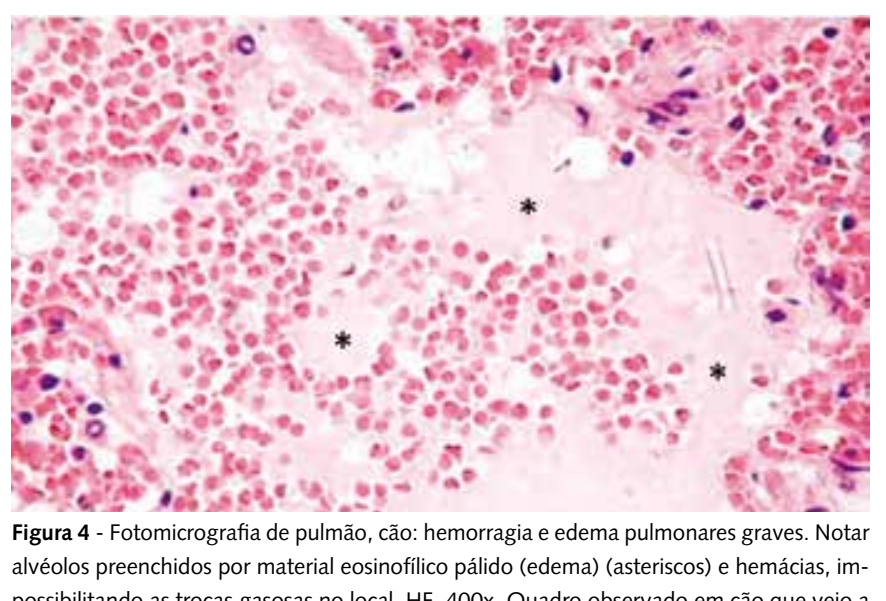
avéolos preenchididos por material eosinofilico palido (edema) (asteriscos) e hemácias, impossibilitando as trocas gasosas no local. HE, $400 \mathrm{x}$.
obito durante os procedimentos de ban ho 
Durante os procedimentos de banho e tosa, é de venha a óbito em seu estabelecimento, podendo resextrema importância a minimização do estresse nos animais. Os fatores que podem alterar o comportamento do animal e gerar estresse incluem a temperatura da água e do secador, odores fortes, barulho excessivo ou repentino, presença de animais agitados em um mesmo recinto e, principalmente, o soprador, que é um equipamento e, principalmente, o soprador,
que produz som alto e repentino.

A presença do proprietário durante os procedimentos de banho e tosa pode, por vezes, alterar o comportamento do animal, seja de maneira positiva ou negativa. Durante a primeira visita, é importante que o cão ou gato possa observá-lo através de um vidro. Com base em seu comportamento, positivo ou negativo, percebe-se se a presença do proprietário aumenta ou diminui os sinais do estresse. Tal atitude é de extrema importância, tanto para o bem-estar do animal, como para a integridade física e psicológica do tosador e banhista.

Os proprietários dos animais devem estar cientes dos riscos envolvidos nos procedimentos de banho e tosa principalmente para gatos, animais agitados, doentes ou idosos. cipalm tosa deve ser transmitida ao proprietário por meio de um tosa deve ser transmitida ao proprietário por meio de um
termo de consentimento livre e esclarecido, assinado por termo de consentimento livre e esclarecido, assinado po ambas as partes e arquivado no estabelecimento.

Recomenda-se a avaliação dos parâmetros fisiológicos do animal pelo médico veterinário antes de qualquer procedimento, seja ele estético ou não, e caso o animal apresente qualquer alteração, o proprietário deverá ser informado.

De acordo com a Resolução $\mathrm{n}^{\circ}$ 878, de 15 de fevereiro de 2008, do Conselho Federal de Medicina Veterinária, é obrigatória a presença de um médico veterinário no estabelecimento de banho e tosa (CFMV, 2008). O papel do médico veterinário como responsável técnico do estabelecimento é de extrema importância na prevenção de acidentes e na correta orientação aos funcionários e aos proprietários dos animais. Além disso, uma vez que o óbito por estresse em animais ocorre poucos minutos após o surgimento dos sinais, a presença do médico veterinário é fundamental para a tentativa de reversão do quadro ou ressuscitação.

$\mathrm{O}$ quadro de funcionários do estabelecimento, banhistas e tosadores, deve ser formado por profissionais altamente qualificados capazes de aplicar o conhecimento teórico e prático adquirido nos cursos para saber reconhecer imediatamente as mudanças físicas e compossíveis óbitos.

Os médicos veterinários devem ficar atentos para possibilidade de implicações legais caso algum animal ponder legalmente nos âmbitos civil,

Vale lembrar ainda que o serviço de banho e tosa configura juridicamente uma relacão de consumo, conforme prietário do animó précich o o fornecedor de tais serviços, que responde pelos danos causados aos consumidores por serviços prestados de maneir nadequada (BRASIL, 1990)

Na última década, no Brasil, foi observado um aumento na demanda para a solução de crimes contra os espaço (SALVAGNI et. al, 2012). Esta demanda parte da própria sociedade que movida pelo sentimento moral ambiental, tem se mobilizado para promover a reform do Código Penal Brasileiro no relativo aos maus-tratos de animais (YOSHIDA. SIQUEIRA; MAIORKA, 2014). Marlet e Maiorka (2010) analisando os registros

o Nú Crininalsica de Sao Paulo (NAT/IC), de 2003 a 2007 Crininalica de Sao Paulo (NAI/IC), de 2003 a 2007 con anim, dos quis $42 \%$ en cas, $16 \%$ en gas contra os animais, dos quais $42 \%$ em cães, $16 \%$ em gatos e $6 \%$ outras espécies.

Um dos principais instrumentos da medicina veterinária legal que colaboram para a resolução dos caso de obitos de animais e a necropsia documentada com utilizada nos casos de óbitos de animais com potencia jurídico, como nas suspeitas de maus-tratos, traumas mprudências e negligências (SALVAGNI et. al, 2014). O registro fotográfico da necropsia é de extrema importância uma ve que as fotos apresentam potencil de prova mo crova m caso juridico, principala Detering se a sinção ocon

Determinar se a situação ocorrida com o animal fo intencional ou não, é uma grande barreira a ser superada pela justiça. É muito importante que seja utilizado um senso comum, combinado com a experiência par análise de todas as informaçôes $e$ a determinação $d$ probabilidade da situação ocorrida ter sido intencional. A interpretação dos relatos dos proprietários e das testemunhas é outro ponto critico na hora da coleta de informações (MERCK, 2007).

Independentemente da situação ocorrida ter sido intencional, sempre que houver a morte de um animal, uma necropsia deve ser realizada para determinar a causa de morte (PARRY, 2008). Se houver suspeita de maus-tratos, com base na Lei Federal 9605/98 art. 32 o proprietário animais, o que fez a medicina veterinária legal ganha fins periciais. Esse tipo de necropsia vem sendo muito poderá entrar com uma ação jurídica contra o estabelecimento, (BRASIL, 1998).

Considerações finais

Proprietários de animais e donos dos estabelecimentos de banho e tosa devem estar cientes dos riscos envolvidos durante a realização de tais procedimentos.

A responsabilidade pela execução do banho e tosa é inteiramente do estabelecimento, que deve agir com diligência e respeito com os animais e com os seus proprietários.

Adotando-se todas as medidas de segurança, com fundamental presença de um médico veterinário no estabelecimento e a adequada qualificação dos funcionários, poderão ser reduzidos significativamente o número de óbitos registrados em tais ocasiões e ser, proporcionada saúde e o bem-estar aos animais.

\section{Referências}

RS 15 bilhöes e já representa $0,31 \%$ do PIB naciona 2014. Disponivel em: <http://abinpet.org. br/imprensa/noticias/abinpet-divulgadados-
mercado-pet-2013/>. Acesso em: 4 jan. 2015 . RHANT, C., BUBNA-LITTITZ: H." BARTELS, A., FUTSCHIK, A., TROXLER, J. Behaviour of smaller and larger dogss effects of training methods, inconsistency of owner behaviou
and level of engagement tin activities with the dog. Applied Animal Behaviour Science. 123, n. 3, p. 131-142, 2010

EAVER, B. V. Introduçăo ao Comportamento dos Felinos. In: BEAVER, B. V. .

BRASIL. Lei № 9.605, de 12 de Fevererio de 1998. Dispõe sobre as sançöes penats adm

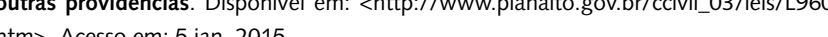
CFMV. Resolução n^ 878, de 15 de fevereiro de 2008. Regulamenta a fiscalização de pessoas juridicicas cujas atividades compreendam a prestaçäo de serviços de estética 2015.

BRASIL. Lei No 8.078 , de 11 de setembro de 1990. Dispōe sobre a protecăa do consumidor e dá outras providências. Disponivivel
ccivil _o3/leis/18078.htm>. Acesso em: 18 maio 2015 .

GGERA, R. A. SOUZA, T. M. SILVA, M. C. BRUM J. S. G: GRACA. D. L. KOMMERS, G D.; IRIGOYEN, L. F; ; BARROS, C. S. L. Causas de morte e razzöes para eutanásiá de cáses Brasileira, v. 28, n. ., . p. 223-230, 2008

FINGLAND, R. B. Doenças obstrutivas de vias respiratórias superiores. In: BIRCHARD, S J.; SHERDING, R. G. (ES)
Roca, 2008. p. 1686.

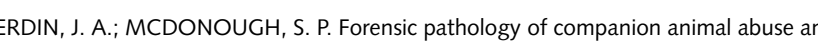
neglect. Veterinary Pathology, v. 50, n. 6, p. . 994-1006, 2013.

MARIA, A.C. B. E. P. Principais alteraçoces encontradas em necropsias de caèes e gatos que vierar a bobito durante procedimentos em petshops s similares. 2010, $114 f$. Dissertaçăo
MARIA, A. C. B. E; REGO, A. A. M. S; MAIORKA, P. C. Necropsy findings in dogs that died during grooming or MARLET, E. F.; MART RA, P. C. Analiser retrospectiva de casos de maus tratos contrac cáes gatos na ciddade de Săo Paulo. Brazilian Journal of Veterinary Research and Animal MOBERC, C. P. B. Biology response to stress: implications for animal welfare. In: MOBERC, G. P.; MENCH, I. A. The biology of animal stress: basic principiles and implications for MUNRO, H. M. C.: THRUSFIELD, M. V. 'Battered pets'. non-accidental physical injuries
found in dogs and cats. Journal of Small Animal Practice, V. 42, n. 6, p. 279-290, 2001. PACAK, K.; MCCARTY, R. Acute stress response: experimental. In: FINK, G. (Ed.). Encyclopedia of stress. San Diego: Academic Press, 2007, v. 1, p. 7-14.

PARRY, N. M. A. Investigating cases of sudden and unesper
patients. Companion Animal, v. 13, n. 9, p. 31-37, 2008 . SALVACNI, F. A.; SIQUEIRA, A; MARIA, A. C. B. E.; SANTOS, C. R.; RAMOS, A. T.i
MAIORKA, P. C. Forensic Veterinary Pathology: Old Dog Learns a Trick. Brazilian Journal of Veterinary Pathology, v. $5, p .37-38,2012$.

SALVAGNI, F. A.; SIQUEIRA, A; MARIA, A. C. B. E.; MESQUITA, L. P.; MAIORKA, P.

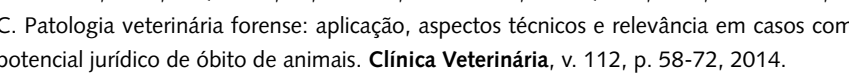
SELYE, H. A syndrome produced by diverse noccuous agents. Nature, v. 138, n. 3479, p.

SELYE, H. The birth of the G.A.S. In: EELYE, H. Stress of life. New York: McGraw-Hill Book Company, 1956, p. 25-43.

YOSHIDA, A. S. Si SIQUEIRA, A.; MAIIORKA, P. C. Importância do médico veterinário no levantamento de provas em crimes de maus tratos. Revista CFMV, v. 63, p. 55-60, 2014. 